\title{
EDITORIAL
}

\section{Standards and Technical Excellence}

\author{
Paul S. Gill
}

T echnical excellence influences the development of uniformity of practices, resulting in standards which may be applied throughout an organization, resulting in reduced costs, mitigated risks and commonality of practices. Initiatives which address the enhancement of an organization's technical excellence are the key to an organization's maintaining of a high level of performance in current programs and projects as well as preparing for new ones. Technical excellence is the goal of all organizations and individuals, whether in government or private industry, national or international ones. But, what do we mean by technical excellence? Most people have their own ideas and interpretation as to what constitutes technical excellence. According to the dictionary, excellence is defined as the state, quality, or condition of excelling; superiority. To excel is to be better than, or to surpass, others. We believe most, if not all, people would be comfortable with this definition. It may be appropriate to explore some statements which have been made concerning technical excellence. One author defined technical excellence as an effort to ensure that well-considered and sufficient technical thoroughness and rigor are applied to programs and projects under an uncompromising commitment to safety and mission success, while another author identified four guiding principles towards achieving technical excellence; (1) Clearly documented proven policies and procedures, (2) Effective training and development, (3) Engineering excellence, and (4) Continuous communications. According to Chris Scolese, Director of the NASA Goddard Space Flight Center, two fundamental attributes must be considered when pursuing technical excellence: (1) Personal accountability, whereby each individual must understand and believe that he or she is responsible for the success of the organization's mission, and (2) Organizational responsibility, whereby the organization provides proper training, tools, and environment. It has also been noted that due to the rapidly expanding technology and science, engineers and technologists in the 21st century must have a strong technical background in their fields as well as understand technology at the interface between traditional fields. They must be creative, skilled problem solvers who can think critically using sound principles and concepts. Technical excellence, and thus good standards, is a product of these principles. In the aerospace arena, one can certainly equate organizational technical excellence and thus have proven engineering and the use of technically proven standards to mission success. In the final analysis, technical excellence is one of, if not the most important goals of any organization. How one achieves and maintains it is a whole other matter, for which there is no simple answer. Unquestionably, an organization with recognized technical leaders who have vision, superior technical competence, and the desire to excel, will achieve technical excellence. The development of proven standards is certainly a product of this goal. Thus, technical leadership is the key for an organization's success as well as the ability of the managers responsible for the carrying out of the organization's mission. Technical excellence is also related to the strategic management of an organization's human capital, and is an organization's most critical asset in accomplishing its mission. Therefore, ensuring the continued development of scientific and technical expertise is necessary in order to preserve an organization's - and the nations' role as a leader in technology. It is also significant to produce good standards and, accordingly, their application. In 2007, NASA undertook a technical excellence initiative in order to identify and solve engineering challenges. The initiative was designed as to provide quality solutions and work which will translate into an agency investment strategy for application into present and future missions. Among the attributes of this 
initiative are the improvement of overall technical capability; the development of analysis and testing, beneficial to multiple missions, programs, and projects; the advancement towards tool/technique capability; and proven standards. In 2006, the aerospace industry released a position paper which demands for standards based on technical excellence of content rather than the source of a standard. Experts from the Aerospace Industries Association's Strategic Standardization Forum (SSFA) for Aerospace prepared a position paper on the use of standards in response to the growing concern that certain policies and legislation may be putting the industry - and consumers - at risk. The SSFA emphasized that the aerospace industry must select standards based on safety, quality, and technical merit, rather than based on which organization developed them. Thus, the authors of the paper recognized technical excellence in relation to ensuring that proven standards are produced and applied in order for good engineering to be achieved. Technical excellence is crucial in the ensuring of compatibility and interoperability of a system's architecture. Proven standards, also referred to as good standards, are important in order to achieve this goal. Perhaps it would be best to, once again, consult the dictionary for what is meant by the term "standard". It means, among other things, "a degree or level of requirement, excellence, or attainment". It is this meaning that we associate with good standards and their role in achieving the success of a program or project. The motivations for good standards and the associated enhancement of technical excellence vary considerably. One most often sees economic issues as their main motivation. Applications to regulatory matters are another strong motivation factor. Among the main motivations for good standards are international competitiveness; commodity confidence; safeguards for health, safety, and environment; risk reduction; facilitation of commercial communications; and technology transfer. However, enhancing organizational capabilities and technical excellence, although readily recognized as a key motivation, is not often seen in the list of motivations for the development and promotion of good standards. In 2012, the World Standards Cooperation Newsletter emphasized that "Good standards are technologyindependent. A good standard helps companies build products that work and communicate with each other anywhere in the world. Standards are an integral part of all organizational product development efforts. Designers and development engineers should be among the most aggressive supporters of technical standards. Standardization activities establish engineering and technical applications for processes and practices and, in doing so, enhance all organizational capabilities, further promoting technical excellence. Thus, they enable an organization to not dissipate its energies on the costly exercise of "reinventing the wheel". The integration of good standards is one step towards the goal of significantly enhancing an organization's technical capabilities and products. Technical excellence is the key to the nation's future in the rapidly growing globalization of the industry. For any country to remain competitive and to maintain its technical leadership in the world, enhancing the nation's capabilities is critical. These capabilities may be acquired only by achieving technical excellence, which is a requirement for good systems' engineering. Good standards provide a major opportunity to achieve the goal of enhancing organizational capabilities and providing a means whereby technical excellence may be infused into the development and the manufacturing process. In many cases, the existing standards, or the requirements within them, are so well established that, without the existence of good examples highlighting a deficiency or weakness in the standard, it is hard to advocate a need for change, and therefore the use of technical excellence as to substantiate a change, and thus illustrate the importance of technical excellence. Enhancing an organization's capabilities and products is an important product of standards, especially when coupled with allied information such as lessons learned and experiences with the use of a standard. Such must be the thrust of any viable organization. This is reinforced and expanded, based on feedback from an organization's staff, its contractors, and on the users of its products, in order to improve the content of the standards. Such feedback, in turn, helps industry to meet demands for timely, productive, and reliable systems, as well as to contribute to improvements in efficiency and costs. Proven standards play an important role in the transfer of technical experiences, lessons learned, best practices, and infusion of new technology for the further enhancement of technical excellence within all organizations. Although technical excellence is not easy to be quantified, there is no doubt it is readily recognized, both by those involved in standards use and development activities and by those who are the "customers", be they public, government, or industry. 